\title{
SDU\%
}

\section{A Leverage-Based Measure of Financial Stability}

by

Tobias Adrian, Karol Jan Borowiecki and Alexander Tepper

Discussion Papers on Business and Economics

No. $1 / 2018$

FURTHER INFORMATION

Department of Business and Economics

Faculty of Business and Social Sciences

University of Southern Denmark

Campusvej 55, DK-5230 Odense M

Denmark

E-mail: lho@sam.sdu.dk / http://www.sdu.dk/ivoe 


\title{
A Leverage-Based Measure of Financial Stability
}

\author{
Tobias Adrian, Karol Jan Borowiecki, Alexander Tepper*
}

February 7, 2018

\begin{abstract}
The size and the leverage of financial market investors and the elasticity of demand of unlevered investors define MinMaSS, the smallest market size that can support a given degree of leverage. The financial system's potential for financial crises can be measured by the stability ratio, the fraction of total market size to MinMaSS. We use that financial stability metric to gauge the buildup of vulnerability in the run-up to the 1998 Long-Term Capital Management crisis and argue that policymakers could have detected the potential for the crisis.
\end{abstract}

Keywords: Leverage, financial crisis, financial stability, minimum market size for stability, MinMaSS, stability ratio, Long-Term Capital Management, LTCM

JEL Classification Numbers: G01, G10, G20, G21

*Tobias Adrian: International Monetary Fund, tadrian@imf.org. Karol Jan Borowiecki: University of Southern Denmark, kjb@sam.sdu.dk. Alexander Tepper: Columbia University, at3065@columbia.edu. The authors thank Itay Goldstein, Neil Grossman, Knick Harley, Howard Jones, Richard Sylla, and Ken Tremain for insightful comments. The views expressed in this paper are those of the authors and do not necessarily reflect the views of the International Monetary Fund. 


\section{Introduction}

Financial crises are difficult to predict as they are triggered by the realization of adverse shocks which tend to be unforecastable. However, the financial systems' vulnerability to adverse shocks is measurable. When system vulnerability is high, shocks can trigger adverse feedback loops via amplification mechanisms such as leverage spirals. Hence financial stability monitoring efforts focus on measuring the degree of financial vulnerability by gauging the evolution of amplification mechanisms in the financial system (see Adrian et al., 2015).

In this paper, we study a particularly important amplification mechanism for financial crises based on the leverage cycle of financial market investors. We develop a theoretical setting of leveraged and unleveraged financial market investors to derive a metric of aggregate leverage that gives rise to a quantitative condition for stability. The stability condition can be evaluated from observable characteristics and can give policymakers advance warning of financial crises.

We define a financial market equilibrium as unstable when the process of tatonnement pushes the system away from, rather than towards, equilibrium (Hahn, 1982). This corresponds to a situation where demand rises with price, and does so faster than supply. It is well-known that levered investors may have upwardsloping demand curves. When the proportion of levered investors is too large the aggregate demand curve for assets can become upward sloping, leading to an unstable equilibrium. Prices can thus exhibit discontinuous akin to financial crises. We develop a quantitative condition for such a market instability.

We show how this financial stability metric could have been used in the context of the 1998 Long-Term Capital Management (LTCM) crisis. That crisis is particularly relevant to our setting as it resulted from the interplay of leveraged financial market investors that resulted in abrupt price changes which can be rationalized 
within our setting. In our application, we show that our calibrated instability coefficients were not large enough to destabilize equity or Treasury markets, but that they could have been large enough to destabilize bank funding and equity volatility markets. The consequences of this potential instability eventually prompted the Federal Reserve to step in and coordinate a private-sector bailout.

Our modeling approach centers on leverage constraints. The related literature falls into three main categories. The first focuses on the impact to the real economy of credit constraints tied to net worth. Seminal contributions in this area are Bernanke and Gertler (1989) and Kiyotaki and Moore (1997), who show that negative net worth shocks force the most productive entrepreneurs to liquidate and have persistent effects on the economy. A second strand of the literature evaluates the effect of collateral requirements specifically on financial markets, showing how forced liquidations from negative net worth shocks can lead to large fluctuations in asset prices (Geanakoplos (2003), Fostel and Geanakoplos (2008), Yuan (2005), Xiong (2001), Adrian and Shin (2010), Chowdhry and Nanda (1998), Acharya and Viswanathan (2011), and Gromb and Vayanos (2010)). A third strand of the literature has examined feedback loops when small shocks cause cascading liquidations through channels other than collateral constraints. These include fund redemptions (Shleifer and Vishny, 1997), price movements interpreted as fundamental signals (Brunnermeier and Pedersen, 2009; Diamond and Verrecchia, 1980; Gennotte and Leland, 1990), tightening margin requirements (e.g., Brunnermeier and Pedersen, 2009; Fostel and Geanakoplos, 2008), or uncertainty about bank solvency (Gorton and Metrick, 2012). Our theoretical setting produces similar dynamics to these three strands of the literature, but relies on more general assumptions about the behavior of financial market participants.

Section 2 develops a simple, intuitive version of the model. Section 3 fully generalizes the model to a degree that permits it to be used in the real world. As 
part of the generalization, we show that the use of financial derivatives is equivalent to leverage and is usually more likely to create the conditions for instability. We will also see that when levered investors participate in multiple markets, a crash in one market can lead to contagion to other markets. Section 4 applies our measure of financial instability to the 1998 collapse of hedge fund Long-Term Capital Management. Section 5 concludes.

\section{The Basic Model}

In our model there are four types of agents: levered investors, who are confident that maximally leveraged positions are permitted by their lenders; fully funded investors, who have a downward-sloping demand curve for assets and who deposit any excess funds in a bank account; banks, who provide credit to the levered investors at the market interest rate and a fixed margin requirement (the reasons for these assumptions are discussed later); and a central bank, whose sole function is to hold interest rates fixed in the near term by providing credit to the market against sound collateral.

Our key assumption about the behavior of levered investors is that they are extremely enthusiastic about assets, so that purchases are leveraged to the maximum degree that lenders permit. Such seemingly simplistic behavior is made for tractability. This assumption can in fact be supported by appropriate microfoundations; the literature investigating optimal portfolio choice in the presence of net worth constraints and credit constraints finds that sufficiently optimistic rational agents do indeed employ leverage to the maximum degree permitted by their lenders (e.g., Grossman and Vila, 1992; Liu and Longstaff, 2004). ${ }^{1}$

\footnotetext{
${ }^{1}$ Even if real-world levered investors have some slack and cushion built in for the short term, investors still tend to target a certain leverage ratio over the medium term: they voluntarily liquidate when their net worth declines in order to avoid forced liquidations later, so they face what is effectively a "soft" margin requirement, see, for example, Shleifer and Vishny (1997)
} 
As a result of these assumptions about levered investor's behavior, their net worth is then given by:

$$
\begin{aligned}
& \text { Net Worth }=(\text { Margin Percentage }) \cdot(\text { Assets }) \\
& \equiv \lambda \cdot p_{t} m_{t}^{l v}
\end{aligned}
$$

where $p_{t}$ is the price of the asset at time $t, m_{t}^{l v}$ is the quantity of the asset held by the levered investor at time $t$ and $\lambda$ is the margin requirement imposed by lenders or by regulators (the minimum proportion of the investor's assets that have to be covered by equity). A margin requirement of five percent $(\lambda=0.05)$, for example, would indicate that at least five percent of the investor's assets have to be covered by equity.

Each period, the investor will reap the benefit of all price appreciation and dividends $d_{t}$ from the assets and pay interest rate $r_{t}$ charged on margin loans, so the change in net worth will be given by:

$$
\begin{aligned}
\Delta N W^{l v} & =\text { Appreciation }+ \text { Dividends }- \text { (Margin Interest }) \\
& =\left(p_{t}-p_{t-1}\right) m_{t-1}^{l v}+d_{t} \Delta t \cdot m_{t-1}^{l v}-(1-\lambda) r_{t} \Delta t \cdot p_{t-1} m_{t-1}^{l v}
\end{aligned}
$$

Adding (2) at time $t-1$ and (4), and simplifying, we have:

$$
N W_{t}^{l v}=m_{t-1}^{l v} \cdot\left[p_{t}+d_{t} \Delta t-(1-\lambda)\left(1+r_{t} \Delta t\right) p_{t-1}\right]
$$

This equation says simply that net worth is given by the current value of last period's assets, plus any dividends received on those assets, minus the value of debt (with interest) funding those assets.

The enthusiastic investor invests her profits back into the asset with leverage. 
A combination of (2) and (5) simplifies to:

$$
m_{t}^{l v}=\frac{m_{t-1}^{l v}}{\lambda} \cdot\left[1+\frac{d_{t} \Delta t-(1-\lambda)\left(1+r_{t} \Delta t\right) p_{t-1}}{p_{t}}\right]
$$

This gives the levered investors' demand for assets $m_{t}^{l v}$ as a function of the price $p_{t}$. The numerator within the bracket is almost certainly negative and hence the levered investors' demand for assets is upward-sloping. ${ }^{2}$ Investors targeting a specific leverage ratio demand more of an asset as its price increases. Finally, leverage introduces path-dependent demand; levered investors' demand depends on both yesterday's holdings and yesterday's price.

There is much to be gained from this approach. No empirically ungrounded assumptions are required about the functional forms of preferences or processes. We are able to incorporate heterogeneity without having to worry about strategic or game theoretic effects. Relying on previous findings of optimizing behavior allows us to avoid the mathematical complexities of nesting optimization within our model. This means that the model is far more tractable, and therefore more transparent about what is driving the results.

The remaining investors who invest without leverage are termed fully funded investors. These investors are not modeled in detail, but are assumed to have a downward-sloping demand curve for assets. This downward-sloping (rather than horizontal) demand may be for a variety of reasons, including heterogeneity of opinion about the value of the asset, relative value considerations, and the desire for portfolio diversification. ${ }^{3}$ More simply, investors who eschew the use of leverage are

\footnotetext{
${ }^{2}$ The only way it is not is when both the time step between margin checks is large and the dividend is very large compared to the margin interest rate. To see how unlikely this is, consider the case where $\Delta t=1$, that is, portfolio reallocations and margin calls take place only once a year. Consider a high capital ratio of $90 \%$ (nine dollars of equity for every dollar of debt), and a margin interest rate of just $1.5 \%$. The dividend yield would then have to be greater than $10.15 \%$ in order for the demand curve to be downward-sloping.

${ }^{3}$ Relative value is a method of determining an asset's value by considering the value of similar assets. The value investor does not invest into the more overvalued asset, which puts downward pressure on its price. Portfolio diversification is when an investor wishes to keep a fixed proportion
} 
limited in their asset purchases by their equity, and so the maximum number of shares they are able to purchase is a declining function of the share price. Demand by fully funded investors is then given by:

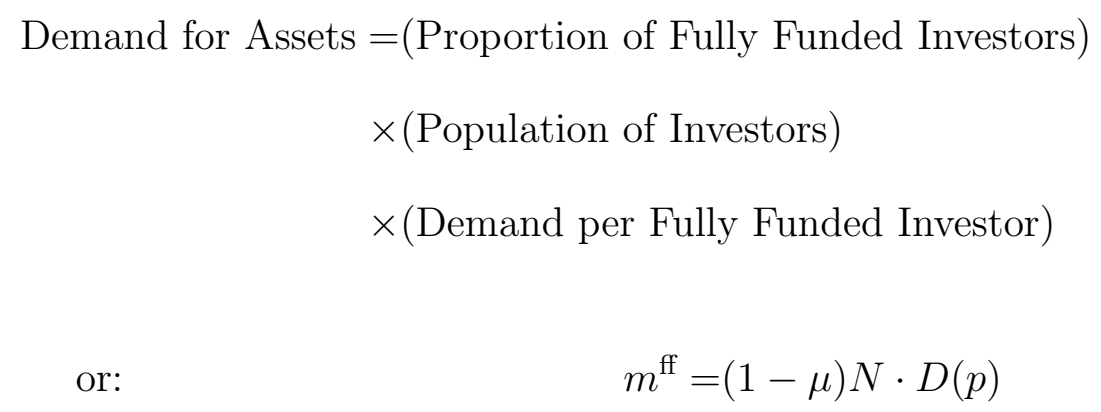

where $m_{t}^{\mathrm{ff}}$ is the total demand for assets by fully funded investors, $\mu$ is the proportion of investors that are levered, $N$ is the total number of investors in the economy and $D(p)$ is the number of assets that the average fully funded investor demands as a function of price. We shall assume that $D^{\prime}(p)<0$ so that demand is downwardsloping and demand does not depend upon the investor's net worth. ${ }^{4}$

Banks are assumed to be conduits that lend to all comers against collateral at of her portfolio in different assets, such as the orthodox portfolio split of $60 \%$ stocks and $40 \%$ bonds. As the price of stocks rises, she needs to hold fewer shares to account for $60 \%$ of her portfolio.

${ }^{4}$ This is an abstraction which is unlikely to be correct in the real world. However, the dependence on price can capture this effect at each moment in time, since we have not specified a functional form. At first glance, it might appear that wealth effects could be large enough that they make fully funded investors' demand upward-sloping. Closer examination reveals that this is not the case. Suppose that unlevered investors hold a proportion of their wealth $\beta(p)$ in an asset, and that they have net worth $y$. Then the number of units of the asset each fully funded investor demands is given by:

$$
D(p)=\frac{y \beta(p)}{p}
$$

Differentiating in logs gives:

$$
\frac{d \log D(p)}{d p}=\frac{1}{y} \frac{d y}{d p}-\frac{1}{p}+\frac{\beta^{\prime}(p)}{\beta(p)}
$$

The last term in this equation is negative. After examining the first term, we shall see that it is always outweighed by the second term, so that demand remains downward-sloping. Suppose that the unlevered investor owns $m$ assets at price $p$, and has additional assets $y_{0}$. Then

$$
y=p m+y_{0}
$$

and

$$
\frac{1}{y} \frac{d y}{d p}=\frac{m}{p m+y_{0}}<\frac{1}{p}
$$

for $y_{0}>0$. So the demand curve remains downward-sloping. 
the prevailing interest rate, which is fixed by a central bank, and with a fixed margin requirement. The existence of banks links the money supply to credit growth and hence links monetary policy to credit provided to speculative endeavors. While the model could work just as well without banks, we include them in order to ensure we meet adding-up constraints.

\subsection{Model Dynamics}

The model's dynamics are governed largely by the behavior of the levered and fully funded investors. We shall investigate how the model behaves over short periods of time, where interest and dividend payments can be neglected.

The total demand for the asset, $m_{t}$, is the sum of the demand by levered and fully funded investors:

$$
\begin{aligned}
m_{t} & =m_{t}^{\mathrm{ff}}+m_{t}^{l v} \\
& =(1-\mu) N \cdot D\left(p_{t}\right)+\frac{m_{t-1}^{l v}}{\lambda} \cdot\left[1-\frac{(1-\lambda) p_{t-1}}{p_{t}}\right]
\end{aligned}
$$

It is clear that if $(1-\mu) N \cdot D(p)$ is large compared to $m_{t-1}^{l v}$, the fully funded investors will dominate and the demand curve will be downward-sloping, with the supply-demand diagram for securities appearing like panel A of Figure 1. However, if levered investors begin to do well, reinvest their proceeds and accumulate the asset, $m_{t-1}^{l v}$ will begin to grow large relative to $(1-\mu) N \cdot D(p)$.

Eventually, the market reaches a tipping point. If levered investors get infinitesimally richer, the demand curve deforms itself from a curve like $D$ into a backward-bending curve like $D^{\prime}$ in panel $\mathrm{B}$ of Figure 1. This infinitesimal change in the levered investors' fortunes changes the character of the system. Point $E$ becomes an unstable equilibrium: any slight positive demand shock (to curve $D^{\prime \prime}$ in 
panel C) would result in excess demand but a lower equilibrium price at point $E^{\prime \prime}$. The demand shock would thus result initially in a price that was above equilibrium but with excess demand. The excess of buyers over sellers would push the price up further, resulting in still greater excess demand. The price would explode upward until it reached a price so high that even levered investors were not willing to buy, and this high price would be the new equilibrium.

Similarly, a slight negative demand shock when the market reaches its tipping point (for example from curve $D^{\prime \prime}$ inward to $D^{\prime}$ ) will result in excess supply but a higher equilibrium price, with no mechanism to pull the price back up to equilibrium. Supply exceeds demand, resulting in price declines, leading to even greater excess supply. A slight increase in demand therefore results in the price exploding to a very high level; a slight decrease in demand results in the price crashing to the point where fully funded investors can absorb all the assets.

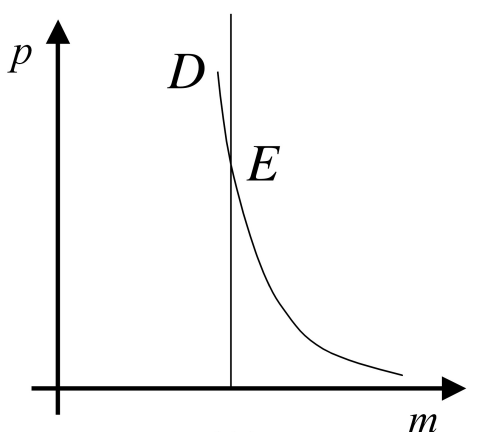

(A)

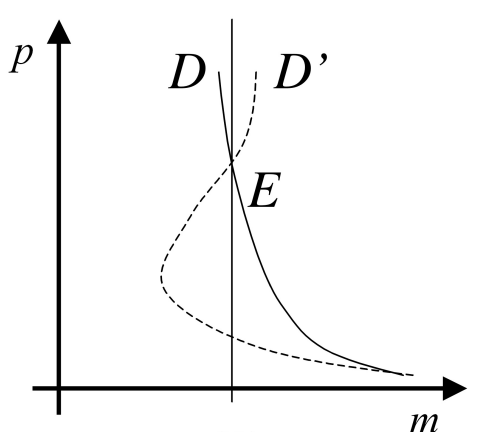

(B)

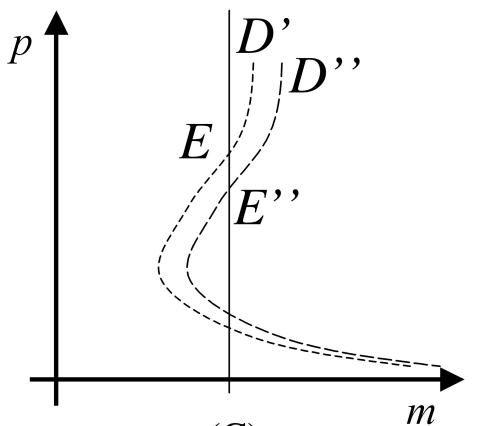

(C)

Figure 1: Supply and Demand with Levered Buyers

Appendix A explains how this process would unfold in a market where, like many financial markets, the price-discovery mechanism is a limit order book. If the demand curve is upward-sloping a negative shock to the price of an asset would result in mass liquidations. This event is usually referred to in the literature and the popular press as "panic" selling, which seems to imply that it is somehow irrational or incomprehensible. It is neither; in this model the mass liquidations are a required response to a decline in asset values. 
Equation (11) determines when the system will exhibit explosive behavior. If its derivative is positive, at the previous period's equilibrium demand slopes upward. The system is unstable and a crash or price spike will result. Otherwise it is stable. Let us examine this formally. Differentiating (11), we have:

$$
\frac{d m_{t}}{d p_{t}}=(1-\mu) N \cdot D^{\prime}\left(p_{t}\right)+\frac{(1-\lambda)}{\lambda} \frac{p_{t-1} m_{t-1}^{l v}}{p_{t}^{2}}
$$

If we know $D^{\prime}(p)$, the demand response of the fully funded investors to small changes in price, we thus can determine whether the system is stable.

Define $A(p) \equiv(1-\mu) N p D(p)$ to be the total dollar amount fully funded investors in the aggregate wish to hold of the asset. Substituting into equation (12) and rearranging, the condition for stability $\left(\frac{d m_{t}}{d p_{t}}<0\right)$ then becomes:

$$
\frac{N W_{t-1}^{l v}}{\lambda^{2}}+\left(1-\eta_{D}\right) A\left(p_{t}\right)<p_{t-1} m_{t-1}^{l v}+A\left(p_{t}\right)
$$

where $\eta_{D}$ (a positive number) is the fully funded investors' price elasticity of demand $-p D^{\prime}(p) / D(p)$. The right hand side of the equation is the market size: the total assets held by levered investors, plus the total assets held by fully funded investors.

The left-hand side of equation (13) is the net worth of levered investors divided by the square of the margin requirement, plus the amount unlevered investors hold of the asset adjusted for their elasticity of demand. This quantity defines the minimum market size for stability of the market, which we shall term MinMaSS. It is the smallest market size that is consistent with stability; if $\eta_{D}=1$ then MinMaSS is just the net worth of levered investors divided by the squared leverage ratio. We can form a ratio of market size to MinMaSS; we call this the stability ratio. If the stability ratio is greater than one, the market is stable; if it is less than one, the market is unstable. We can use the stability ratio in a straightforward way to 
determine how stable is the market. The closer is the stability ratio to one, the closer is the market to becoming unstable.

Higher margin requirements support stability with a higher share of levered investors, while a relatively small number of levered investors can create instability if leverage is high. For example, suppose levered investors have a 10\% margin requirement $(\lambda=0.1)$ and the elasticity of demand $\eta_{D}$ is 1 . Then levered investors will only need net worth of $1 \%$ of the total demand for the asset to create an unstable situation. This suggests that instability in markets may not be a particularly rare state of affairs. On the other hand, if the capital ratio is moderate, say 1:1, levered investors will need net worth of $25 \%$ of the total demand for the asset to create an unstable situation. A lower capital buffer is so dangerous because, as equation (13) shows, MinMaSS goes as the square of the margin requirement $\lambda$.

Once the stability ratio is below one and the market becomes unstable, one of two events occurs. Either there is an immediate crisis where the price crashes and levered investors go bankrupt, or the price explodes up to the maximum levered investors will pay (call this $v_{\pi}$ ). The speed of this explosion prevents levered investors from fully levering their net worth to buy the assets without driving the price up past $v_{\pi}$. After such an explosion, a small shock to fully funded investors' demand does not change the price at all; levered investors simply adjust their holdings to absorb the shock. However, if a downward shock to fully funded investors'demand is large enough, the levered investors may be forced to fully lever to absorb the shock. At this point, any additional shock will reduce the price of the asset below $v_{\pi}$ and will force liquidations. The levered investors will be constrained again and the demand curve below $v_{\pi}$ will be given by equation 11 . This means we can still use equation 13 to assess the stability of the market. However, it is important to note that the relevant margin requirement $\lambda$ is the minimum leverage ratio required by financial regulators (or targeted by investors), rather than the actual margin 
requirement observed in the market. ${ }^{5}$

In summary, MinMaSS is determined by the characteristics and holdings of levered investors and by the demand curve of fully funded investors. Instability results from insufficient capital: If levered investors grow in the market, their perverse demand curves overwhelm the downward-sloping demand from more prudent investors, eventually causing total demand to become upward-sloping. This makes the typical equilibrium between supply and demand an unstable "knife edge" with no mechanism to force a convergence to that equilibrium. The lower capital ratio that is required, the more fragile the market in the sense that it takes a smaller share of levered investors to cause an unstable situation.

\section{An Operationalizable Version of the Model}

We have so far restricted ourselves to a market with only one asset, no short-selling, and only one class of levered investors, a choice made for expositional clarity. In this section, we expand the MinMaSS framework to incorporate markets where different investors lever to differing degrees, markets where investors sell short and take positions using derivatives, and markets with multiple assets, which will give rise to contagion. The resulting measure accounts for sufficient diversity that it might be used by macroprudential regulators as an early warning sign against financial crises.

Let us suppose that there are many assets, indexed by $j$, and that each asset has some derivative contracts associated with it, indexed by $\delta$. Levered investors are indexed by $i$ and have net worth $N W_{i}^{l v}$. Each asset has a collateral value, the maximum amount that can be borrowed against it, which may vary by investor. If

\footnotetext{
${ }^{5}$ This minimum capital ratio may be more difficult to observe than actual leverage. In general, using actual rather than minimum margin requirement would bias the estimate of MinMaSS downward and thus lead to insufficiently conservative policy, because higher minimum capital leads to lower MinMaSS, ceteris paribus.
} 
the price of asset $j$ at time $t$ is $p_{t}^{j}$, then its collateral value for investor $i$ is defined to be $\left(1-\lambda_{i}^{j}\right) p_{t}^{j}$. Each derivative contract $\delta$ on asset $j$ must be also collateralized. At each time $t$, investor $i$ allocates a proportion of her net worth $\pi_{i t}^{j \delta}$ (which may be a function of the price vector $\mathbf{p}_{\mathbf{t}}$ ) to collateralize each asset and derivative contract in which she invests. As above, we assume that levered investors are leverage-constrained, meaning they use all their capital: $\sum_{j \delta} \pi_{i t}^{j \delta}=1$.

Each investor's direct demand for the asset is given by the quantity she can buy with the share $\pi_{i t}^{j}$ of her net worth she devotes to that asset:

$$
\text { Direct Demand }=\frac{\text { Capital Devoted to Asset }}{\text { Margin Requirement per Unit }}=\frac{\pi_{i t}^{j} N W_{i t}^{l v}}{\lambda_{i}^{j} p_{t}^{j}} \equiv m_{i t}^{j d}
$$

With regard to derivatives, we consider contracts with single-period margining, meaning that any changes in fair value of the contract are paid or received each trading period. The most common examples of such contracts are exchange-traded futures and options contracts, although most credit default swaps and interest rate swaps have similar features.

The value of each derivative contract $\delta$ on asset $j$ is a function of the price of the asset, which we shall denote $f_{j \delta}\left(p_{t}^{j}\right)$. We treat a short sale as the special derivative contract where $f(p)=-p$. For each investor $i$, asset $j$, derivative contract $\delta$, and time $t$, we shall say that she holds $C_{i t}^{j \delta}$ derivative contracts. For each of these contracts, she must post a fixed dollar amount of collateral $\chi_{i t}^{j \delta}$ as initial margin with the exchange or counterparty.

We assume that levered investors may be on either the long or short side of the derivative contracts, so that $C$ may be positive or negative. Of course, every derivative contract has two sides, so the net supply of derivative contracts must be identically equal to zero. Therefore, we introduce market makers who are assumed to absorb any disparity in demand between long and short speculative positions and 
hedge these positions in the cash market. For each derivative contract, the position $C_{h t}^{j \delta}$ held by market makers is just the inverse of the net position of the levered investors:

$$
C_{h t}^{j \delta}=-\sum_{i} C_{i t}^{j \delta}
$$

In order to be hedged, a market maker wishes to be indifferent to price changes in the underlying asset. She therefore demands assets $m_{t}^{h}$ according to the condition:

$$
\frac{d}{d p_{t}}\left[C_{h t}^{\delta} f\left(p_{t}\right)+m_{t}^{h} p_{t}\right]=0
$$

or

$$
m_{t}^{h}=-C_{h t}^{\delta} f^{\prime}\left(p_{t}\right)=\sum_{i} C_{i t}^{\delta} f^{\prime}\left(p_{t}\right)
$$

The market maker is thus "delta hedging" with $\Delta \equiv C_{h t}^{\delta} f^{\prime}\left(p_{t}\right)$. Each investor $i$ makes a contribution to the market maker's delta hedging activities for derivative contract $\delta$ in proportion to the investor's holdings. It therefore makes sense to refer to this contribution as the investor's indirect demand for the asset:

$$
\text { Indirect Demand }=C_{i t}^{j \delta} f_{j \delta}^{\prime}\left(p_{t}^{j}\right)=\sum_{\delta} \frac{\pi_{i t}^{j \delta} N W_{i t}^{l v}}{\chi_{i t}^{j \delta}} \cdot f_{j \delta}^{\prime}\left(p_{t}^{j}\right)
$$

Investor $i$ 's total effective demand for asset $j$ is the sum of direct and indirect demand:

$$
m_{i t}^{j}=\frac{\pi_{i t}^{j} N W_{i t}^{l v}}{\lambda_{i}^{j} p_{t}^{j}}+\sum_{\delta} \frac{\pi_{i t}^{j \delta} N W_{i t}^{l v}}{\chi_{i t}^{j \delta}} \cdot f_{j \delta}^{\prime}\left(p_{t}^{j}\right)
$$

At this point it is helpful to bring in two concepts from the options pricing literature and practice, delta $(\Delta)$ and gamma $(\Gamma)$. Delta and gamma will be the building blocks of our stability analysis. For each investor $i$ and asset $j$, her $\Delta_{i t}^{j}$ is the change in her net worth for every dollar increase in the price of asset $j$. That is:

$$
\Delta_{i t}^{j} \equiv \frac{\partial N W_{i t}^{l v}}{\partial p_{t}^{j}}
$$


To get an explicit expression for $\Delta$, we differentiate each investor's net worth this period with respect to the price of a specific asset $j^{\prime}$ to obtain $m_{i, t-1}^{j^{\prime}}$. The investor's $\Delta$ is thus her total net effective demand for the asset.

We will also be interested in gamma $(\Gamma)$. For each investor $i$ and asset $j, \Gamma_{i t}^{j}$ measures the change in the investor's exposure to the asset as its price changes, assuming she does not actively adjust her positioning. It represents the convexity of her net worth relative to the price of asset $j$. By definition gamma is the price derivative of delta:

$$
\begin{aligned}
\Gamma_{i t}^{j} & \equiv \frac{\partial \Delta_{i t}^{j}}{\partial p_{t}^{j}} \\
& =\sum_{\delta} \frac{\pi_{i, t-1}^{j \delta} N W_{i, t-1}^{l v}}{\chi_{i, t-1}^{j \delta}} \cdot f_{j \delta}^{\prime \prime}\left(p_{t}^{j}\right)
\end{aligned}
$$

These definitions of delta and gamma are analogous to those in the options literature (e.g., Hull, 2006).

\subsection{Stability Analysis}

As with our previous analyses, the market for each asset $j$ will be stable if demand is downward-sloping. As before, we add fully funded investors with a downwardsloping demand curve:

$$
m_{t}^{j, \mathrm{ff}}=(1-\mu) N D_{j}\left(p_{t}^{j}\right)
$$

The total demand curve is just the sum of the demand of all the investors:

$$
m_{t}^{j, T O T}=\sum_{i} m_{i t}^{j}+m_{t}^{j, f f}
$$


The slope of the demand curve is:

$$
\begin{aligned}
\frac{d m_{t}^{j, T O T}}{d p_{t}^{j}} & =\sum_{i} \frac{d m_{i t}^{j}}{d p_{t}^{j}}+(1-\mu) N D_{j}^{\prime}\left(p_{t}^{j}\right) \\
& =\sum_{i} \frac{d m_{i t}^{j}}{d p_{t}^{j}}-\frac{\eta_{j} A}{p_{t}^{j 2}}
\end{aligned}
$$

where $\eta_{j}$ (a positive number) is the elasticity of demand of fully funded investors and $A$ is the total value of the assets they hold, as before.

Expanding the total derivative in terms of partial derivatives, and conducting a number of transformations (which are described in detail in Appendix B), gives the slope of the demand curve in terms of $\Delta$ and $\Gamma$ as:

$$
\frac{d m_{t}^{j, T O T}}{d p_{t}^{j}}=\sum_{i}\left[-\frac{m_{i t}^{j}}{p_{t}^{j}}+\Gamma_{i, t+1}^{j} \cdot \frac{f^{\prime \prime}\left(p_{t}^{j}\right)}{f^{\prime \prime}\left(p_{t+1}^{j}\right)}+\frac{\Delta_{i, t+1}^{j} \Delta_{i t}^{j}}{N W_{i t}^{l v}}+\sum_{\delta} \frac{\partial m_{i t}^{j}}{\partial \pi_{i t}^{j \delta}} \frac{\partial \pi_{i t}^{j \delta}}{\partial p_{t}^{j}}\right]-\frac{\eta_{j} A}{p_{t}^{j 2}}
$$

Note that while some of the subscripts in this equation have the value $t+1$, these values are nonetheless all known at time $t .^{6}$

To find MinMaSS and evaluate the stability of an equilibrium, we will be interested in the sign of this derivative in steady state, i.e. when $p_{t+1}^{j}=p_{t}^{j}$. In other words, if $p_{t}^{j}$ is an equilibrium, is it stable?

The condition for stability in asset market $j$ is that $d m^{T O T} / d p<0$. Imposing this condition, dropping the now superfluous subscripts $j$ and $t$, and rearranging terms gives another form of the stability condition:

$$
\sum_{i} N W_{i}^{l v} \cdot\left(p \Delta_{i} / N W_{i}^{l v}\right)^{2}+p^{2}\left\{\sum_{i} \Gamma_{i}+\sum_{\delta i} \frac{\partial m_{i t}^{j}}{\partial \pi_{i}^{\delta}} \frac{\partial \pi_{i}^{\delta}}{\partial p}\right\}+(1-\eta) A<\sum_{i} p m_{i}+A
$$

We define the left-hand side of equation (28) as MinMaSS; the right side is the actual

\footnotetext{
${ }^{6}$ Mathematically, this can be seen in Appendix B in the transformation from equation (33) to (34).
} 
market size, given by the total assets of the levered investors, plus total assets of the fully funded investors. ${ }^{7}$ The four terms on the left side of equation (28) determine the minimum market size for stability.

In the first term, each investor makes a contribution to MinMaSS that is proportional to the square of her $\Delta$ relative to her net worth. Recall that $\Delta$ tells us the dollar amount that an investor's net worth changes for each dollar change in the price of an asset. The expression $p \Delta / N W^{l v}$ is therefore a measure of leverage. Indeed, in the simple case where there are no derivative contracts and an investor is invested in only one asset, $p \Delta / N W^{l v}$ is precisely equal to the conventionally defined leverage ratio.

Equation 28 therefore shows that each levered investor makes a contribution to MinMaSS in proportion to her net worth and the square of her leverage. This non-linearity means that a single investor can have a large impact on the market. The fact that contribution to MinMaSS is proportional to delta squared also means that a levered investor always makes a destabilizing contribution, whether she is long or short. If two levered investors enter into a futures contract, taking offsetting positions, both investors increase their squared delta and thus both contribute positively to MinMaSS. MinMaSS and instability increase with the total absolute value of levered investors' positions, not their aggregated net position, meaning that derivatives used for speculative purposes increase instability in proportion to the square of the net open interest in the contract.

\footnotetext{
${ }^{7}$ Equation (28) gives the stability condition where the independent variable is the price of an asset. However, many fundamentals-based investors consider relative value in their asset allocation decision, so that their demand for an asset depends not only on the price $p^{j}$ of asset $j$ but also on the price level of assets generally. It is easy to incorporate this into equation 28 via a change of variable. For example, we might let $P$ be the general level of asset prices and $q^{j}=p^{j}-P$ be the idiosyncratic component of the price of asset $j$. Then $\partial / \partial q^{j}=\partial / \partial p^{j}$, so the equation does not change, but on the right side the elasticity $\eta$ has a slight definitional change, and becomes:

$$
\eta=\frac{\left(q^{j}+P\right) \cdot\left[\partial D^{j}\left(P, q^{j}\right) / \partial q^{j}\right]}{D^{j}\left(P, q^{j}\right)}
$$
}


This term also contains a contagion effect. If the price of another asset falls, so that the net worth of an investor decreases while $\Delta^{j}$ stays constant, the first term in equation (28) will increase, MinMaSS will rise, and the market will move closer to instability.

The second term of equation (28) is more subtle, but it will be intuitive to derivatives market participants as representing purchases or sales by market markers as a part of their delta-hedging activities. This term arises because the value of a derivative in general will not be linear in the price of the underlying asset (long options positions have positive convexity, for example). As a result, if the price of the underlying asset changes, $f^{\prime}(p)$ will change, and the market maker will no longer have a neutral stance with respect to the price of the asset (that is, equation (17) will no longer be satisfied). The market maker will therefore have to adjust her position in the underlying asset to remain hedged. This change in hedging demand in response to price is what is described by the second term, and it shows that levered investors contribute to instability and MinMaSS in proportion to their net gamma position.

Because gamma only arises in relation to open derivative contracts, the total gamma in the market is zero. ${ }^{8}$ However, we need to exclude from our calculation the gamma position of market makers, so this term will not in general be zero, although it is likely to be quite small compared to the first term. This leads to the interesting prediction that when levered investors sell volatility, stability in the underlying market is enhanced..$^{9}$

The third term in equation (28) captures the contribution to MinMaSS from

\footnotetext{
${ }^{8}$ Recall that if the value of an investors' portfolio is a function $v(p)$ of the underlying price of the asset, then $\Gamma=v^{\prime \prime}(p)$. If the investor holds only outright long or short positions and has not entered into derivatives contracts, then the value of her portfolio is simply proportional to the price $p$, and $\Gamma=v^{\prime \prime}(p)=0$.

${ }^{9}$ This phenomenon was confirmed in a conversation with a market participant who managed a large portion of the derivatives portfolio: he told us that when a large investor writes options, market makers delta-hedging their positions are forced to buy when the market falls and sell when it rises, reducing volatility.
} 
levered investors rebalancing their portfolios in response to price movements. In practice, this term is likely to be negative, though this is not certain; sufficiently inelastic substitution away from appreciating assets can cause levered investors actually to increase the proportion of net worth held in an asset as its price rises.

The fourth term in equation (28) is the elasticity-adjusted amount unlevered investors hold of the asset. This term is negative for $\eta>1$. In this case, the greater share of assets held by fully funded investors, the lower is MinMaSS and the more stable is the market, all else equal.

Each levered investor contributes to instability in proportion to the square of her leverage $(\Delta)$ and in proportion to her net volatility position $(\Gamma)$. In practice, all the information necessary to evaluate the stability condition defined by equation (28) could be collected by a systemic regulator and straightforwardly aggregated to evaluate the stability of the market. While such an undertaking may sound daunting, in fact the information is simply a standard set of summary statistics of the portfolios of investors and is already compiled daily (or even more frequently) by all sophisticated investors in their risk reports.

Previous literature has measured financial stability empirically via market based measures such as CoVaR (Adrian and Brunnermeier, 2016), asset quality (Kamada and Nasu, March 2010) and the credit-to-GDP ratio (Borio and Lowe, 2002), among other metrics. In the next section we argue that MinMaSS is a complementary metric to consider by applying the metric to the 1998 collapse of the hedge fund Long-Term Capital Management. 


\section{The Collapse of Long-Term Capital Manage-}

\section{ment}

We now apply the model to the 1998 collapse of hedge fund Long-Term Capital Management and show that it risked destabilising those markets where it was both highly levered and relatively large. A number of previous authors have examined the near-collapse of LTCM, including Perold (1999), Jorion (2000), Schnabel and Shin (2004), and Dungey et al. (2006)).

LTCM was a large relative value hedge fund that was in business from 1994 until 1999. ${ }^{10}$ The hedge fund employed a strategy of relative value arbitrage, in which it bought some assets it considered to be relatively cheap while selling short other, very similar assets it considered to be relatively expensive. ${ }^{11}$ Relative value hedge funds are typically highly levered institutions, and LTCM was perhaps the archetype of such a fund. LTCM was also very large: at its peak in April 1998 it had $\$ 4.87$ billion in capital, $\$ 125$ billion in assets, and another $\$ 115-125$ billion of net notional value in off-balance sheet derivatives. ${ }^{12}$

For the first several years of its existence, Long-Term's results were spectacular, and the fund grew as it succeeded. However, as it grew it attracted imitators both

\footnotetext{
${ }^{10}$ The historical facts in this narrative are taken largely from Lowenstein (2000), Dunbar (2000), and MacKenzie (2003), as well as conversations with former LTCM principals who wish to remain anonymous.

${ }^{11}$ An example of a typical trade would be for LTCM to buy a 29 1/2-year Treasury bond and sell short a 30-year Treasury bond. LTCM made money because the 30-year bond was more liquid, so it traded with a slightly lower yield (i.e., higher price). After six months, the Treasury would issue a new 30-year bond, and the 30-year bond LTCM had sold short would become a 29 1/2-year bond while the 29 1/2-year bond it owned would become a 29-year bond. Because the 29 1/2-year bond has similar liquidity characteristics to the 29-year bond, the yields would converge, and LTCM could liquidate the trade at a profit. More examples of LTCM's trades can be found in Perold (1999).

${ }^{12}$ Other sources generally report a figure of $\$ 1.25$ trillion in off-balance sheet derivatives. However, this figure fails to take into account that many of these positions were not just negatively correlated but in fact perfectly offsetting, that is, long and short exactly the same instrument. This is because LTCM, like other market participants, typically engaged in an offsetting trade when it wanted to close out a swap contract, rather than ending or selling the original contract. The so-called "replacement value" of these swaps was \$80-90 billion (Interview with LTCM Principal, 2010), and equity derivatives accounted for an additional $\$ 35$ billion (Dunbar, 2000).
} 
in the hedge fund community and among the trading desks of the Wall Street banks, leading returns and opportunities to dwindle (see Table 1). LTCM's troubles began in late spring of 1998 and continued into the summer 1998, especially when Salomon Brothers, whose trading behavior was close to that of LTCM, began to close down its arbitrage desk, both to reduce risk and in response to poor results.

\begin{tabular}{c|c|c|c|} 
Date & $\begin{array}{c}\text { Beginning Assets under } \\
\text { Management (Net Capital) }\end{array}$ & Annualized Return & $\begin{array}{c}\text { End of Period Leverage } \\
\text { (Excluding Derivatives) }\end{array}$ \\
\hline $3 / 94-2 / 95$ & $\$ 1.1$ billion & $25 \%$ & 16.7 \\
$3 / 95-2 / 96$ & $\$ 1.8$ & $50 \%$ & 27.9 \\
$3 / 96-2 / 97$ & $\$ 4.1$ & $34 \%$ & 27.9 \\
$3 / 97-2 / 98$ & $\$ 5.8$ & $11.5 \%$ & 26.8 \\
$3 / 98-7 / 98$ & $\$ 4.7$ & $-35 \%$ & 31.0
\end{tabular}

Table 1: LTCM Performance and Leverage Ratio, Excluding Derivatives. Source: Perold (1999)

In August and September, LTCM began to lose money in a dramatic fashion. However, LTCM's principals found themselves unable to liquidate to reduce risk at anything close to what they viewed as a reasonable price. Other market participants moved to liquidate ahead of LTCM, pushing prices against it and causing even deeper distress (Lowenstein, 2000; Perold, 1999). ${ }^{13}$

By the end of September, LTCM had barely been able to reduce its risk at all and its capital had been severely depleted. The Federal Reserve, cognizant that a default could result in a sudden liquidation of a portfolio that included $\$ 125$ billion in assets and $\$ 1.25$ trillion gross notional value of derivatives, and that this could destabilize markets, stepped in to orchestrate a bailout by LTCM's counterparties. $^{14}$

We will never know for certain whether fears of a severe financial disruption

\footnotetext{
${ }^{13}$ Partner Eric Rosenfeld compared LTCM to a large ship in a small harbor in a storm-it was too large to maneuver, and all the other boats were just trying to get out of its way (Rosenfeld, 2009).

${ }^{14}$ As then-Chairman Alan Greenspan put it, "our sense was that the consequences of a fire sale. . should LTCM fail on some of its obligations, risked a severe drying up of market liquidity." (Greenspan, 1998) New York Fed President McDonough said, "there was a likelihood that a number of credit and interest rate markets would experience extreme price moves and possibly cease to function for a period of one or more days and maybe longer." (McDonough, 1998)
} 
would have been realized had LTCM been allowed to fail. We can, however, examine how the MinMaSS framework could have been used to assess whether financial markets would have suffered from an episode of instability had LTCM been forced to liquidate. We shall find that the instability might have occurred in at least a few of the markets in which Long-Term played.

\subsection{Stability of LTCM's Markets}

We now examine LTCM's impact on the stability of global equity markets, global equity volatility markets, US bank funding markets and US Treasury markets in the late summer of $1998 .^{15}$ Bank funding and equity markets are two of the most economically significant and transparent markets in which LTCM operated, and accounted for a significant portion of the fund's risk. Furthermore, the bank funding market is of particular systemic importance since a dysfunctional bank funding market may cause contagious bank failures. ${ }^{16}$

Hard portfolio data on LTCM and its competitors are very difficult to come by because there were no public reporting requirements and the funds were very secretive while they were trading. Because of the media scrutiny to which LTCM was subject after the crash, some of the partners in the fund were more forthcoming than they had been previously, and some information is available on its portfolio. This information has been compiled from a number of media and academic sources, as well as a discussion with former LTCM principals. Information on the size of markets has been compiled from public sources such as the flow of funds accounts

\footnotetext{
${ }^{15}$ While other funds and banks had made similar trades, these funds are considered here as behaving like fully funded investors since they were generally not facing distress and forced liquidations.

${ }^{16}$ The choice of these markets has been informed by the positions LTCM held, and in some sense seems obvious. We can use the MinMaSS framework to examine the stability of any market segment we can define. However, the narrower the definition of the market, the more elastic is the demand of unconstrained investors, and thus the smaller is the minimum market size for stability. When market size is larger, the levered investor such as LTCM must control a larger overall proportion of the market to destabilize it.
} 
from the Federal Reserve. ${ }^{17}$

LTCM's largest equity trades were sales of volatility on broad stock indexes in the US and Europe. ${ }^{18}$ According to Dunbar (2000), by January 1998 LTCM's 5-year equity option position was about $\$ 100$ million per percentage point of volatility. Using the Black-Scholes option pricing formula, this implies that LTCM had written options with a notional value of about $\$ 11.5$ billion (see Appendix C.1 for the calculation). The consequences of this position for stability in the equity market can be examined utilizing equation (28). For stability of the equity market as a whole, the consequences of LTCM's distress were small. LTCM's hedges meant that it had no exposure to outright stock price movements - it had a $\Delta$ of zero. Its $\Gamma$, however, (or $p^{2} \Gamma$ ) was about $\$ 10$ billion (see Appendix C.2 for the calculation).

Plugging these figures into equation (28), assuming no changes in LTCM's portfolio distribution and assuming the elasticity of fully funded demand to be equal to one, gives a MinMaSS in the equity markets of $\$ 10$ billion. The US and European equity markets at the time were larger than this by a factor of over a thousand, implying a negligible stability ratio. Clearly, a forced liquidation of LTCM was nowhere near enough to destabilize the equity markets. Indeed, while equity markets declined along with most risk assets during the summer of 1998, they never ceased to function in an orderly manner.

The market for equity volatility was affected, however. LTCM's sales of volatil-

\footnotetext{
${ }^{17}$ Data for LTCM's competitors and copycats, in particular large investment banks and hedge funds, is even more scarce. The investment banks that were competing with LTCM were required to publicly report losses at the time of the collapse of LTCM, but these were generally only on an aggregate basis. Their arbitrage portfolios were only a part of the proprietary trading businesses. Similarly, LTCM's hedge fund competitors were under no obligation to disclose their holdings and took care not to do so. However, these funds tended to be both significantly smaller and less levered than LTCM (Anonymous, 1998), meaning that for our theory they contribute far less to MinMaSS. Note that contributions to MinMaSS are proportional to fund capital and to the square of leverage. If our calculation was extended by data for firms that had similar trades to LTCM, the estimated MinMaSS would have been higher and the market closer to instability. Set against this, however, is that the other firms were not in financial distress and hence forced to liquidate.

${ }^{18}$ More background on these trades, and the reasons behind them, are described in Dunbar (2000); Lowenstein (2000); Perold (1999).
} 
ity were one of the trades that also hurt it the most, with losses of $\$ 1.3$ billion. We can use again equation (28) to determine the stability of the market for volatility by calculating first MinMasSS. We assume no changes in LTCM's asset allocation shares during a forced liquidation, volatility priced around $20 \%$ and $\$ 100$ million exposure per point of volatility. ${ }^{19}$ This translates into LTCM having sold short $\$ 2$ billion of volatility. ${ }^{20}$

We now calculate the total market size. According to Dunbar (2000) and Lowenstein (2000), LTCM was responsible for about a quarter of the long-term volatility sales, while the investment banks were responsible for the rest, meaning that the demand for volatility on the part of unlevered investors, $A$, was about $\$ 8$ billion. This volatility was mainly sold to pension funds and unit trusts that had promised their owners a minimum rate of return.

Since $p m$ is LTCM's position (negative $\$ 2$ billion), the actual market size is therefore $\$ 6$ billion, and the stability ratio, given by the ratio of MinMaSS and actual market size, simplifies to:

$$
\text { Stability ratio }=\frac{1}{3}(5-4 \eta)
$$

Assuming the elasticity of unconstrained demand to be equal to one (i.e., $\eta=1$ ), the stability ratio is 0.33 (Table 2). If the elasticity of demand of unlevered investors was less than 0.5, then MinMaSS would have been higher than $\$ 2$ billion and the market for volatility would have been unstable. This is not entirely implausible, because the volatility was sold to insurance companies and pension funds that were using it to hedge guaranteed returns on their policies and likely would not have been inclined to sell their options to take advantage of short-term price movements. This shows that LTCM was of the right order of magnitude to destabilize this market.

\footnotetext{
${ }^{19}$ Lowenstein (2000) states that volatility was priced at 19\%, while Perold (1999) cites a figure of $20 \%$.

${ }^{20}$ See to Appendix C.3 for detailed calculations.
} 


\begin{tabular}{l|c|c|c|} 
& Equity Volatility & Bank Funding & US Treasury \\
\hline LTCM Net Notional Exposure $(p \Delta)$ & $-\$ 2$ billion & $\$ 20$ billion & $\$ 20$ billion \\
LTCM Net Worth & $\$ 2.1$ billion & $\$ 2.1$ billion & $\$ 2.1$ billion \\
Notional Position of Unconstrained Investors & $\$ 8$ billion & $\$ 618$ billion & $\$ 5.5$ trillion \\
MinMaSS (Assumes $\eta=1)$ & $\$ 2$ billion & $\$ 200$ billion & $\$ 200$ billion \\
Actual Market Size & $\$ 6$ billion & $\$ 638$ billion & $\$ 5.5$ trillion \\
Stability ratio & 0.33 & 0.31 & 0.04
\end{tabular}

Table 2: Stability Analysis for Selected LTCM Markets

A similar analysis is possible for another of LTCM's trades, a bet on swap spreads, a measure of bank funding costs. Comparison across sources suggests that LTCM's exposure to US swap spreads in the late summer of 1998 was about $\$ 16$ million per basis point of swap spread. ${ }^{21}$ This corresponds to an exposure of about $\$ 200$ million per point of the price of a 10-year bond (MacKenzie, 2003), and therefore a notional exposure of $\$ 20$ billion both to Treasury bonds and to bank credit.

For the bank funding market we have LTCM's position ( $p m=\$ 20$ billion) and assets held by other investors $\left(A=\$ 618\right.$ billion). ${ }^{22}$ Equation (28) implies a MinMaSS of $\$ 200$ billion, if the elasticity of unconstrained demand was equal to one. The associated stability ratio is about 0.3. However, if the demand for bank credit was inelastic $(\eta<$ about $1 / 3)$, then MinMaSS would have moved up towards the market size and the stability ratio would have approached one. In this case, LTCM alone could have been enough to destabilize the market for bank credit.

By contrast, there were around $\$ 5.5$ trillion of Treasury securities outstanding,

\footnotetext{
${ }^{21}$ Lowenstein (2000, p. 187) implies that LTCM's exposure to a 15 basis point adverse move in swap spreads was $\$ 240$ million, which implies an exposure of $\$ 16$ million per basis point. This would imply that the trade lost $\$ 160$ million for LTCM on August 21, 1998, a day when swap spreads moved 10 basis points (although, as many authors note, they moved up to 20 basis points intraday). Overall, LTCM lost $\$ 550$ million on August 21 , of which $\$ 160$ million was due to a merger arbitrage trade gone wrong, and perhaps a bit more was due to increases in equity volatility. This would mean that losses on US 10-year swap spreads were a substantial portion of the remaining losses, which is likely given that this was by all accounts one of LTCM's core trades (see, for example, Perold, 1999). Additionally, a former LTCM principal told us that $\$ 10$ million per basis point was a plausible estimate, which we take to mean that it is within a factor of two.

${ }^{22}$ Assets held by other investors is the sum of $\$ 188.6$ billion owed by commercial banks, $\$ 193.5$ billion owed by bank holding companies, $\$ 212.4$ billion owed by savings institutions, $\$ 1.1$ billion owed by credit unions, and $\$ 42.5$ billion owed by broker-dealers (Federal Reserve Board, 2013), minus the $\$ 20$ billion held by LTCM.
} 
which is around nine times the size of the bank funding markets. This leads to an stability ratio of less than 0.05, so LTCM likely was nowhere near big enough to destabilize the Treasury markets.

Real-world behavior is always more complex than economic models, but the narrative of the rise and fall of LTCM generally corroborates the key behavioral assumptions and predictions of the model. The next section provides an extended discussion of these real-world factors in light of the insights stemming from our model.

A more qualitative investigation shows in Appendix D that LTCM's behavior and financial market dynamics more closely match what is proposed in this paper or earlier models of capital-constrained arbitrage and investing behavior such as Grossman and Vila (1992), Shleifer and Vishny (1997), or Liu and Longstaff (2004), than an unconstrained neoclassical agent. This is true in at least three important respects. First, the size of LTCM's positions during most of its existence was determined much more by its capital than by its assessment of available opportunities. Second, when the market tottered in the summer of 1998, the savviest investors were certain that prices were divorced from fundamental value, a view that was later proved correct. Third, prices in the destabilized markets became ill-defined as liquidity dried up.

\section{Conclusion}

This paper draws a quantitative link between leverage, market size, and financial stability. Markets tend to become unstable when levered investors accumulate too large a share of the asset market. The total net worth and the distribution of net worth held by levered investors together determine a minimum market size for the market to be stable. The ratio of the market size to this minimum market size 
defines a stability ratio which determines how close the market is to instabilityinduced crises.

We apply the model to study the collapse of Long-Term Capital Management in 1998 and how the collapse affected various asset markets. Most accounts of the demise of LTCM argue that the fund's fundamental failure was that it was too highly levered and took too much risk. Lowenstein, Dunbar, the President's Working Group on Financial Markets, and the Basel Committee all accept this hypothesis. Our analysis makes clear that LTCM's leverage was, however, only part of the story. LTCM was both highly levered and large relative to the markets in which it invested. Had it been smaller it might have survived even with its high leverage. LTCM's very existence destabilized markets, creating the potential for much larger price moves than would have been possible in the absence of the fund's existence. Instead of the risks being mitigated by LTCM's hedges, as it would have been had the fund been smaller, once the crisis hit risks became governed by the theoretical notional exposure. All of a sudden, the correlations between the assets LTCM was betting on changed, precisely because LTCM was betting on them.

Our model has advantages relative to other models of financial crises. Our simple framework can accommodate a richness of financial instruments and heterogeneous beliefs, making it easy to apply operationally. The chosen methodological design implies that the results are not sensitive to small changes in model specification. Finally, the key variables in the model are observable and measurable by regulators: leverage, margin requirements, interest rates, and the net worth of levered investors versus unlevered investors. There is a minimum of reliance on unobservable variables such as utility, expectations formation, and subjective probability distributions. The measure we have presented is sufficiently general and simple that it could be calculated and applied by macroprudential regulators to provide advance warning of a crisis, warnings that might prevent or mitigate future crises. 


\section{References}

Acharya, Viral V. and S. Viswanathan, "Leverage, Moral Hazard, and Liquidity," The Journal of Finance, 2011, 66 (1), 99-138.

Adrian, Tobias and Hyun Song Shin, "Liquidity and Leverage," Journal of Financial Intermediation, 2010, 19 (3), 418-437.

- and Markus K. Brunnermeier, "CoVaR," American Economic Review, 2016, 106 (7), 1705-41.

_, Daniel Covitz, and Nellie Liang, "Financial Stability Monitoring," Annual Review of Financial Economics, 2015, 7, 357-395.

Anonymous, "Mosler's Moral: Just Small Enough to Fail," Institutional Investor, October 1998.

Bernanke, Ben and Mark Gertler, "Agency Costs, Net Worth, and Business Fluctuations," American Economic Review, 1989, 79 (1), 14-31.

Borio, Claudio and Philip Lowe, "Asset Prices, Financial and Monetary Stability: Exploring the Nexus," BIS Working Papers, 2002, 114.

Brunnermeier, Markus and L. Pedersen, "Predatory Trading," Journal of Finance, August 2005, LX (4).

Brunnermeier, Markus K. and Lasse Pedersen, "Market Liquidity and Funding Liquidity," Review of Financial Studies, 2009, 22 (6), 2201-2238.

Chowdhry, Bhagwan and Vikram K. Nanda, "Leverage and Market Stability: The Role of Margin Rules and Price Limits," Journal of Business, April 1998, 71 (2).

Coy, Peter and Suzanne Woolley, "Failed Wizards of Wall Street," Business Week, September, 211998.

Diamond, Douglas W. and Robert E. Verrecchia, "Information Aggregation in a Noisy Rational Expectations Economy," Journal of Financial Economics, 1980, 9, 221-235.

Dunbar, Nicholas, Inventing Money: The Story of Long-Term Capital Management and the Legends Behind It, Chichester: Wiley, 2000.

Dungey, Mardi, Renée Fry, Brenda González-Hermosillo, and Vance Martin, "Contagion in international bond markets during the Russian and the LTCM crises," Journal of Financial Stability, 2006, 2 (1), 1-27.

Federal Reserve Board, "Financial Accounts of the United States," September 25, 2013.

Fostel, Ana and John Geanakoplos, "Leverage Cycles and the Anxious Economy," American Economic Review, 2008, 98 (4), 1211-1244. 
Geanakoplos, John, "Liquidity, Default, and Crashes," Cowles Foundation for Research in Economics Working Papers, 2003, $10 \% 4$.

Gennotte, Gerard and Hayne Leland, "Market Liquidity, Hedging and Crashes," American Economic Review, 1990, 80 (5), 999-1021.

Gorton, Gary and Andrew Metrick, "Securitized banking and the run on repo," Journal of Financial Economics, 2012, 104 (3), 425-451.

Gromb, Denis and D. Vayanos, "A model of financial market liquidity based on arbitrageur capital," Journal of European Economic Association, 2010, 8, 456466.

Grossman, Sanford J. and Jean-Luc Vila, "Optimal Dynamic Trading with Leverage Constraints," Journal of Financial and Quantitative Analysis, June 1992, $27(2), 151-168$.

Hahn, Frank, "Stability," in K. J. Arrow and M.D. Intriligator, eds., Handbook of Mathematical Economics, Amsterdam: North Holland Press, 1982.

Hull, John C., Options, Futures and Derivatives, Upper Saddle River, NJ: Prentice Hall, 2006.

Jorion, Philippe, "Risk Management Lessons from Long-Term Capital Management," European Financial Management, 2000, 6, 277-300.

Kamada, Koichiro and Kentaro Nasu, "How Can Leverage Regulations Work for the Stabilization of Financial Systems," Working Paper 10-E-2, Bank of Japan March 2010.

Kiyotaki, Nobuhiro and John Moore, "Credit Cycles," Journal of Political Economy, April 1997, 105 (2), 211-248.

Krugman, Paul, "Balance Sheets, the Transfer Problem and Financial Crises," International Tax and Public Finance, 1999, 6, 459-472.

Liu, Jun and Francis A. Longstaff, "Losing Money on Arbitrage: Optimal Dynamic Portfolio Choice in Markets with Arbitrage Opportunities," Review of Financial Studies, Autumn 2004, 17 (3), 611-641.

Lowenstein, Roger, When Genius Failed: The Rise and Fall of Long Term Capital Management, New York: Random House, 2000.

MacKenzie, Donald, "Long-Term Capital Management and the Sociology of Arbitrage," Economy and Society, August 2003, 32 (3), 349-380.

Perold, Andre, "Long-Term Capital Management L.P.," Harvard Business School Case Studies 200-007/8/9/10, 1999.

Rosenfeld, Eric, "Long-Term Capital Management: 10 Years Later," February 19 2009. Presentation at Sloane School of Business. 
Schnabel, Isabel and Hyun Song Shin, "A model of financial market liquidity based on arbitrageur capital," Journal of European Economic Association, 2004, 2 (6), 929-968.

Shleifer, Andrei and Robert W. Vishny, "The Limits of Arbitrage," Journal of Finance, March 1997, LII (1), 35-55.

Xiong, Wei, "Convergence trading with wealth effects: an amplification mechanism in financial markets," Journal of Financial Economics, November 2001, 62 (2), 247-292.

Yuan, Kathy, "Asymmetric Price Movements and Borrowing Constraints: A Rational Expectations Equilibrium Model of Crises, Contagion, and Confusion," Journal of Finance, 2005, LX (1), 379-411.

\section{Appendix}

\section{A Limit Order Book Price-discovery Mecha- nism}

In this part we explain how the price-discovery mechanism works in a typical financial market affected by a shock to the asset price when the demand curve is upwardsloping. For illustrative purposes, consider the closest situation to the Walrasian case: a market where (unrealistically) the full retail demand curve is expressed in the form of open buy and sell orders in the limit order book. ${ }^{23}$ The levered investors' demand curve below the market price is expressed in terms of stop-loss orders: If the market price falls, these stops convert automatically into sell-at-market orders that are matched against the highest bid. Their demand curve above the market price is expressed as a series of stop-buy orders, which convert into buy orders as the price rises. ${ }^{24}$

Figure 2 visualizes how the limit-order book will change after a negative price shock and upward-sloping demand. The left panel shows the initial limit-order book, where the first column lists the bids, the second the offers, the solid line indicates open orders, the dotted line marks stop orders and the size of each line represents the size of order. Once the tape prints a downtick, the first stop-loss order is activated. It is matched against the highest bid, but because the demand curve is upward-sloping the highest bid is not for a large enough size to fully fill the sell order (middle panel). The part of the sell order that could not be filled jumps to the next lowest price and executes against the next highest bid (right panel). When these orders are matched, the tape prints another downtick, the next stop-loss order is activated, and

\footnotetext{
${ }^{23}$ To be clear, these orders are tied to the derivative of the demand curve; they are the changes in quantity that would be required for each change in price level.

${ }^{24} \mathrm{We}$ assume the levered investors already have finance lined up to purchase additional units when their equity increases.
} 


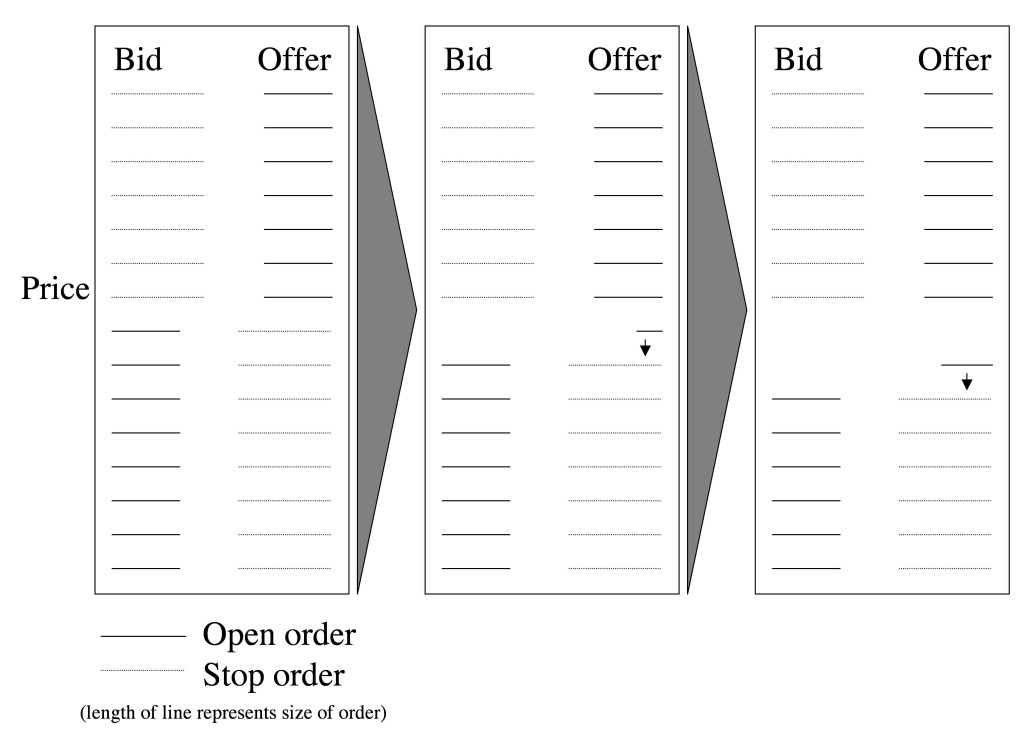

Figure 2: The limit order book and a negative price shock

the process cascades as all the stops are ultimately activated and quickly execute against progressively lower bids as the market crashes to a level where retail investors are able to fully absorb the liquidations by the levered speculators.

Once the liquidations begin, rational non-levered investors, if they understand the process underway, will respond by withdrawing their bids and waiting for the dust to settle at the new equilibrium, rather than supporting the price all the way down. Some of the more sophisticated of these investors will even engage in predatory selling, temporarily worsening the collapse, along the lines of what is modeled by Brunnermeier and Pedersen (2005). The price will gap downwards rather than fall smoothly. After the fall, the model produces a condition of depressed asset prices. Because the levered investors lose their entire net worth, the stock of assets must be held by a smaller group of unlevered investors. These investors have downwardsloping demand, so the asset price must be less than it was before demand became concentrated in a small group of levered investors, as it might in a bubble.

If the initial shock is upward, the result is similar. Theoretically, the upward cascade continues to infinity; in practice it continues until the levered investors have fully exhausted their credit lines and must raise more finance in order to continue to buy assets. These adjustments are not simply an ordinary process of market adjustment to a new, efficient equilibrium. Rather, as in much of the literature on currency crises (for example, Krugman, 1999), multiple equilibria are possible and prices can move discontinuously in response to small shocks. 


\section{B Calculating the Stability Condition}

Expanding the total derivative from equation (26) in terms of partial derivatives, we obtain:

$$
\frac{d m_{t}^{j, T O T}}{d p_{t}^{j}}=\sum_{i}\left[\frac{\partial m_{i t}^{j}}{\partial p_{t}^{j}}+\frac{\partial m_{i t}^{j}}{\partial N W_{i t}^{l v}} \frac{\partial N W_{i t}^{l v}}{\partial p_{t}^{j}}+\sum_{\delta} \frac{\partial m_{i t}^{j}}{\partial \pi_{i t}^{j \delta}} \frac{\partial \pi_{i t}^{j \delta}}{\partial p_{t}^{j}}\right]-\frac{\eta_{j} A}{p_{t}^{j 2}}
$$

We will aim to rewrite this equation in terms of $\Delta$ and $\Gamma$. Working just with the first term, we have:

$$
\begin{aligned}
\frac{\partial m_{i t}^{j}}{\partial p_{t}^{j}} & =\frac{\partial}{\partial p_{t}^{j}}\left[\frac{\pi_{i t}^{j} N W_{i t}^{l v}}{\left(1-\lambda_{i}^{j}\right) p_{t}^{j}}+\sum_{\delta} \frac{\pi_{i t}^{j \delta} N W_{i t}^{l v}}{\chi_{i t}^{j \delta}} \cdot f_{j \delta}^{\prime}\left(p_{t}^{j}\right)\right] \\
& =-\frac{\pi_{i t}^{j} N W_{i t}^{l v}}{\left(1-\lambda_{i}^{j}\right) p_{t}^{j 2}}-\sum_{\delta} \frac{\pi_{i t}^{j \delta} N W_{i t}^{l v}}{\chi_{i t}^{j \delta 2}} \cdot f_{j \delta}^{\prime}\left(p_{t}^{j}\right) \frac{\partial \chi_{i t}^{j \delta}}{\partial p_{t}^{j}}+\sum_{\delta} \frac{\pi_{i t}^{j \delta} N W_{i t}^{l v}}{\chi_{i t}^{j \delta}} \cdot f_{j \delta}^{\prime \prime}\left(p_{t}^{j}\right)
\end{aligned}
$$

If the initial margin on derivative contracts $\chi$ is proportional to the price, as is usual, then we can simplify further:

$$
\frac{\partial m_{i t}^{j}}{\partial p_{t}^{j}}=-\frac{1}{p_{t}^{j}}\left[\frac{\pi_{i t}^{j} N W_{i t}^{l v}}{\left(1-\lambda_{i}^{j}\right) p_{t}^{j}}+\sum_{\delta} \frac{\pi_{i t}^{j \delta} N W_{i t}^{l v}}{\chi_{i t}^{j \delta}} \cdot f_{j \delta}^{\prime}\left(p_{t}^{j}\right)\right]+\sum_{\delta} \frac{\pi_{i t}^{j \delta} N W_{i t}^{l v}}{\chi_{i t}^{j \delta}} \cdot f_{j \delta}^{\prime \prime}\left(p_{t}^{j}\right)
$$

Substituting equation (19) in the first term and equation (22) in the second term gives:

$$
\frac{\partial m_{i t}^{j}}{\partial p_{t}^{j}}=-\frac{1}{p_{t}^{j}}\left[m_{i t}^{j}\right]+\Gamma_{i, t+1}^{j} \cdot \frac{f^{\prime \prime}\left(p_{t}^{j}\right)}{f^{\prime \prime}\left(p_{t+1}^{j}\right)}
$$

We can now substitute equation (34) into the first term in the demand curve (30):

$$
\frac{d m_{t}^{j, T O T}}{d p_{t}^{j}}=\sum_{i}\left[-\frac{m_{i t}^{j}}{p_{t}^{j}}+\Gamma_{i, t+1}^{j} \cdot \frac{f^{\prime \prime}\left(p_{t}^{j}\right)}{f^{\prime \prime}\left(p_{t+1}^{j}\right)}+\frac{\partial m_{i t}^{j}}{\partial N W_{i t}^{l v}} \frac{\partial N W_{i t}^{l v}}{\partial p_{t}^{j}}+\sum_{\delta} \frac{\partial m_{i t}^{j}}{\partial \pi_{i t}^{j \delta}} \frac{\partial \pi_{i t}^{j \delta}}{\partial p_{t}^{j}}\right]-\frac{\eta_{j} A}{p_{t}^{j 2}}
$$

Working now with the third term, we can substitute equation (20) to give:

$$
\begin{aligned}
\frac{\partial m_{i t}^{j}}{\partial N W_{i t}^{l v}} \frac{\partial N W_{i t}^{l v}}{\partial p_{t}^{j}} & =\left[\frac{\pi_{i t}^{j}}{\left(1-\lambda_{i}^{j}\right) p_{t}^{j}}+\sum_{\delta} \frac{\pi_{i t}^{j \delta}}{\chi_{i}^{j \delta}} \cdot f_{j \delta}^{\prime}\left(p_{t}^{j}\right)\right] \cdot \Delta_{i t}^{j} \\
& =\left[\frac{m_{i t}^{j}}{N W_{i t}^{l v}}\right] \cdot \Delta_{i t}^{j} \quad \text { by (19) } \\
& =\left[\frac{\Delta_{i, t+1}^{j}}{N W_{i t}^{l v}}\right] \cdot \Delta_{i t}^{j}
\end{aligned}
$$


Substituting (38) into (35) gives the slope of the demand curve in terms of $\Delta$ and $\Gamma$, as expressed below, or in equation (27).

$$
\frac{d m_{t}^{j, T O T}}{d p_{t}^{j}}=\sum_{i}\left[-\frac{m_{i t}^{j}}{p_{t}^{j}}+\Gamma_{i, t+1}^{j} \cdot \frac{f^{\prime \prime}\left(p_{t}^{j}\right)}{f^{\prime \prime}\left(p_{t+1}^{j}\right)}+\frac{\Delta_{i, t+1}^{j} \Delta_{i t}^{j}}{N W_{i t}^{l v}}+\sum_{\delta} \frac{\partial m_{i t}^{j}}{\partial \pi_{i t}^{j \delta}} \frac{\partial \pi_{i t}^{j \delta}}{\partial p_{t}^{j}}\right]-\frac{\eta_{j} A}{p_{t}^{j 2}}
$$

\section{Calculations}

\section{C.1 LTCM's notional value of the outstanding options}

An investor's exposure to changes in volatility is denoted by the Greek letter vega $(\nu)$. Vega is the derivative of the option price with respect to the implied volatility, or annualized standard deviation of the price of the underlying instrument. LTCM's 5year equity option position was about $\$ 100$ million per percentage point of volatility (Dunbar, 2000), which implies a vega of $\$ 10$ billion. In standard option-pricing notation (see, for example, Hull, 2006), the vega of a put or call option is given by:

$$
\nu=S_{0} \sqrt{T} N^{\prime}\left(d_{1}\right)
$$

where

- $S_{0}$ is the price (or for a portfolio, total notional value) of the underlying asset

- $T$ is the time to expiry

- $N^{\prime}\left(d_{1}\right)$ is the probability density function for the standard normal distribution, $N^{\prime}\left(d_{1}\right)=\frac{1}{2 \pi} \exp \left(-d_{1}^{2} / 2\right)$

- $d_{1}=\frac{\ln \left(S_{0} / K\right)+\left(r-q+\sigma^{2} / 2\right) T}{\sigma \sqrt{T}}$

- $K$ is the strike price of the option

- $r$ is the risk-free rate of interest

- $q$ is the dividend yield on the asset

- $\sigma$ is the implied volatility, in percentage points per year

LTCM traded at-the-money-forward options, which means that $\ln \left(S_{0} / K\right)=-(r-$ q) $T$, simplifying the expression for $d_{1}$. LTCM's vega is thus given by:

$$
\begin{aligned}
\nu & =S_{0} \sqrt{T} N^{\prime}(\sigma \sqrt{T} / 2) \\
(\$ 10 \text { billion }) & =S_{0} \cdot \sqrt{5} \cdot \frac{1}{2 \pi} \exp \left[-(20 \%)^{2} \cdot 5 / 8\right]
\end{aligned}
$$

Solving for $S_{0}$, the notional value of the outstanding options, thus gives $S_{0}=\$ 11.5$ billion. 


\section{C.2 LTCM's $\Gamma$ in the equity markets}

Recall that $\Gamma$ is the derivative of $\Delta$ with respect to the price. The $\Gamma$ of an option is given by Hull (2006) as:

$$
\Gamma=\frac{N^{\prime}\left(d_{1}\right)}{S_{0} \sigma \sqrt{T}}
$$

where the variables are as defined as in Appendix C.1. We care about the $p^{2} \Gamma$ of the portfolio. If the portfolio includes options on $m$ shares of the underlying asset, then the total $p^{2} \Gamma$ in equation (28) is:

$$
\begin{aligned}
p^{2} m \Gamma & =p^{2} m \frac{N^{\prime}\left(d_{1}\right)}{S_{0} \sigma \sqrt{T}} \\
& =\left(p / S_{0}\right) \cdot p m \cdot \frac{N^{\prime}\left(d_{1}\right)}{S_{0} \sigma \sqrt{T}} \\
& =1 \cdot(\$ 11.5 \text { billion }) \cdot \frac{N^{\prime}(20 \% \cdot \sqrt{5} / 2)}{20 \% \sqrt{5}} \\
& =\$ 10 \text { billion }
\end{aligned}
$$

\section{C.3 MinMaSS of the market for equity volatility}

MinMaSS is calculated using the following parameters:

- $\Delta=\$ 100$ million per volatility point

- $p=20$ points

- $N W^{l v}=\$ 2.1$ billion

- $\Gamma=0$

Note that while LTCM's equity in early summer was $\$ 4.5$ billion, only $\$ 2.1$ billion of this was actually required as margin for trades (MacKenzie, 2003), with the rest as risk capital intended to absorb losses. By early September, LTCM had lost its entire risk capital cushion. The $\$ 2.1$ billion is therefore the correct number to consider for the net worth as it was here that liquidations would have been forced. We again assume no changes in LTCM's portfolio balance during a forced liquidation and utilize the left-hand side of equation (28):

$$
\begin{aligned}
\text { MinMaSS } & =p^{2} \cdot\left[N W^{l v} \cdot\left(\frac{\Delta}{N W^{l v}}\right)^{2}\right] \\
& =(20)^{2} \cdot\left[\$ 2.1 b \cdot\left(\frac{-\$ 100 m}{\$ 2.1 b}\right)^{2}\right] \\
& =\$ 2 \text { billion }
\end{aligned}
$$


It is clear from even a casual glance at LTCM's assets and equity (which Perold (1999) has obtained directly from LTCM, Figure 3) that the fund's equity is an important determinant of its assets. As LTCM ramped up its operations and began both to raise and earn capital, it was able to increase its assets as well, although, as Perold points out, the growth in assets outpaced the growth in capital for a time as LTCM built its operations. In fact, LTCM's balance sheet size was, in the early stages of its existence, more governed by right-sizing its assets to meet its capital base than by its assessments of the available arbitrage opportunities in the marketplace.

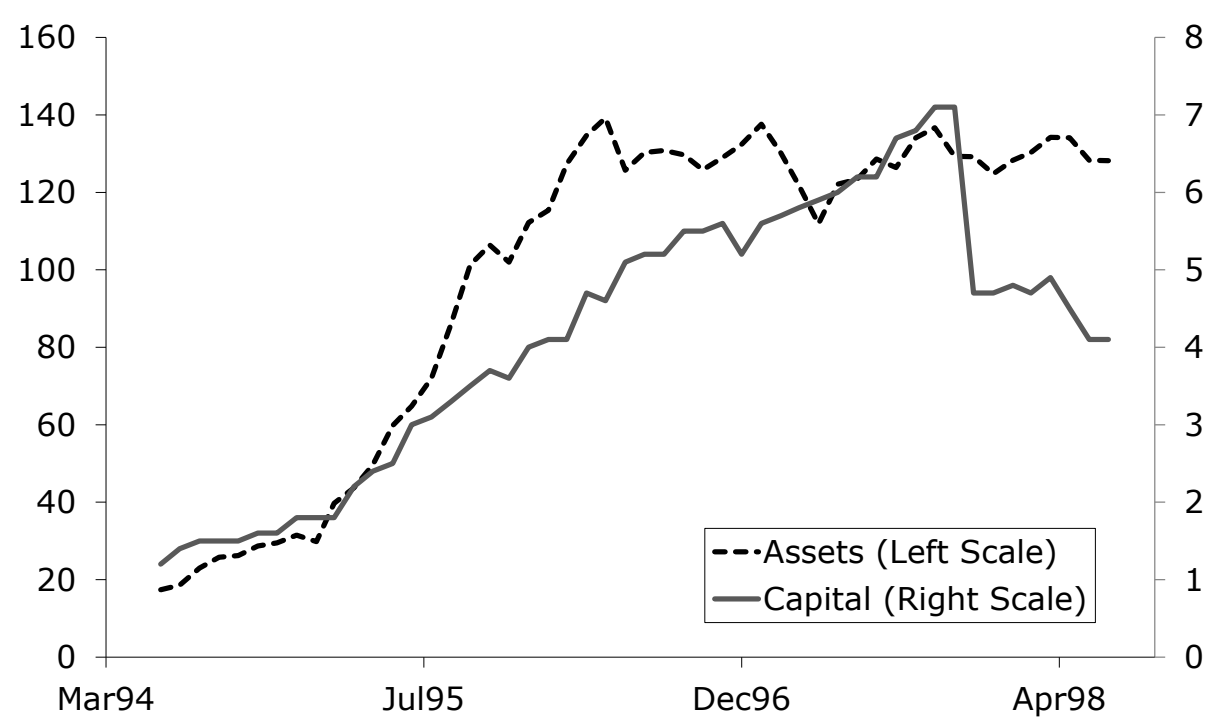

Figure 3: LTCM Assets and Equity Capital Source: Perold (1999)

\section{Corroborating Evidence}

LTCM was not completely price-insensitive in its buying, contrary to what the model assumes about levered investors. Instead, as it grew and was imitated, LTCM noticed that favorable opportunities were "drying up big," as Eric Rosenfeld put it (quoted in MacKenzie, 2003). LTCM reacted by returning capital to investors, putting a ceiling on its willingness to continue its strategy at less and less attractive pricing. This decision to return capital to investors kept LTCM's capital at a level where margin constraints had to be considered. Instability was thus still very much a possibility because, as all the narrative histories of LTCM that we are aware of point out, capital cannot be easily raised by a fund once it begins to lose money and approaches its credit or net worth constraint.

This instability was realized in the summer of 1998 when prices began to move against LTCM. Even at the time, sophisticated market participants understood and commented that asset prices were moving away from fundamental value. As William 
Winters, head of J.P. Morgan's European Fixed Income business, put it at the height of the crisis, "any concept of long-term or fundamental value disappeared" (Coy and Woolley, 1998).

Other bankers agreed that prices were not being driven by fundamental value but by tactical considerations. As one Goldman Sachs trader put it, "If you think a gorilla has to sell, then you sure want to sell first." Goldman CEO Jon Corzine did not deny that the firm "did things in markets that might have ended up hurting LTCM. We had to protect our positions. That part I'm not apologetic about." (Lowenstein, 2000, p. 175) Lowenstein cites similar sentiments from executives at other banks, in particular Salomon Brothers, which had a portfolio of a similar size to LTCM (Dunbar, 2000).

In this situation, a value-oriented, unconstrained investor would be betting on prices to converge. So, too, would a levered investor who saw prices moving against her long-term view, and indeed, this is precisely what LTCM wanted to do. LTCM principals continued to have confidence in their trades even as the market moved further and further against them. As Meriwether put it in his August 1998 letter to investors (reproduced in Perold, 1999):

With the large and rapid fall in our capital, steps have been taken to reduce risks now ... On the other hand, we see great opportunities ... The opportunity set in these trades at this time is believed to be among the best that LTCM has seen ... LTCM thus believes it is prudent and opportunistic to increase the level of the Fund's capital to take full advantage of this unusually attractive environment.

Rosenfeld put it more directly: "We dreamed of the day when we'd have opportunities like this" (Lowenstein, 2000, p. 166).

This was not just talk. No source disputes that Meriwether was actively trying to raise additional capital. As Lowenstein (2000), Dunbar (2000), and others note, the partners' faith in their trades was ultimately proven correct. The consortium of investment banks that took over the fund was left with double-digit returns one year later. Yet as markets were moving against it, creating more attractive opportunities, LTCM was liquidating some trades, adding to the price pressure. According to Dunbar (2000, p. 194), LTCM decided at the end of June to reduce its daily valueat-risk (VAR) from $\$ 45$ million to $\$ 35$ million. ${ }^{25}$

In the markets that LTCM destabilized, prices were not only divorced from fundamental value but in some cases were not even well-defined as liquidity evaporated. The stability ratios presented in Table 2 indicate that LTCM was of the right order of magnitude to destabilize the equity volatility market, but not the equity market. Liquidity conditions during the late summer of 1998 corroborate this finding. Despite significant declines, cash equity markets continued to function normally with reasonable liquidity. The market for long-dated volatility in equities, however, was thrown into disarray and became almost completely illiquid. Trading became very

\footnotetext{
${ }^{25} \mathrm{VAR}$ is a measure of risk, typically quoted as the $95 \%$ confidence interval of daily profit and loss.
} 
sparse and price quotes spiked and became divorced from fundamentals, according to market participants quoted in Dunbar (2000) and MacKenzie (2003).

As one banker said:

When it became apparent that they [LTCM] were having difficulties, we thought that if they are going to default, we're going to be short a hell of a lot of volatility. So we'd rather be short at 40 than 30 , right? So it was clearly in our interest to mark at as high a volatility as possible. That's why everybody pushed the volatility against them, which contributed to their demise in the end. (MacKenzie, 2003)

This quotation demonstrates that in the long-dated volatility markets, prices were not clearly defined. LTCM's counterparties had considerable discretion in what prices to place on the options that LTCM was short. This is only possible in a market that is not liquid. If the market had been active with many participants ready to buy and sell at their estimate of fundamental value, such discretion would not be possible because prices would be determined by the intersection of supply and demand. LTCM was such a big player that the possibility of it being forced to liquidate was enough to prevent prices from being well-defined. This is a hallmark of instability.

Given that the market moves were driven by fear of instability, it is no surprise that LTCM's losses were concentrated in the areas where it had most destabilized markets. Lowenstein $(2000$, p. 234) provides a breakdown, showing that of the $\$ 4$ billion lost by Long-Term in 1998, $\$ 1.6$ billion was in swaps and another $\$ 1.3$ billion in equity volatility. No other category of losses even tops $\$ 500$ million. 